\title{
Endoscopic Findings in Patients with Upper Gastrointestinal Bleeding in Upper Egypt: A Single Centre Study
}

\author{
Mohamed El Badry ${ }^{1}$, Noha Eltaweel ${ }^{2}$, Abdelmajeed Moussa ${ }^{1}$ \\ ${ }^{1}$ Department of Tropical Medicine and Gastroenterology, Faculty of Medicine, Aswan \\ University, Aswan, Egypt. \\ ${ }^{2}$ Department of Medical Molecular genetics, National Research Centre, Cairo, Egypt.
}

Corresponding Author Mohamed El Badry

Mobile:

00201001815738

\section{E mail:} melbadry2002@yahoo. com

Key words: Upper endoscopy, Hematemesis, Melena, Upper Egypt
Background and study aim: Upper gastrointestinal bleeding (UGIB) is a significant cause of medical emergency with high morbidity and mortality. There are different causes of UGIB. Our study aimed to evaluate the endoscopic findings in patients with UGIB.

Methods: This retrospective study was conducted at endoscopy centre, Aswan University Hospital, Aswan, Egypt, over the four years period (2015- 2019). Records of patients with UGIB who underwent upper gastrointestinal endoscopy were reviewed. Data were

\section{INTRODUCTION}

Acute bleeding from upper gastrointestinal tract is a common medical emergency characterized by hematemesis and/or melena. Massive hemorrhage from the upper gastrointestinal tract may be associated with brighter rectal bleeding. Hemodynamic instability may also be a feature; with patients presenting with dizziness, syncope or hypovolemic shock. Despite the declining incidence of upper gastrointestinal bleeding (UGIB)- and besides advances in therapeutic endoscopy and increased use of acid suppressing medication, the inhospital mortality is still significant [1].

The incidence of UGIB in European populations was between $84-160$ cases per 100,000 adults, with the highest incidence being in men, in the elderly and in lower socioeconomic groups [2]. collected then analyzed via SPSS version 20.

Results: This study included records of 918 patients (575 male) with mean age (SD) of 49.38 (14.86) years. Portal Hypertensive disease (PHD) (55.5\%) was the most frequent cause of UGIB, followed by peptic ulcer disease (PUD) (27.1\%) then other causes (17.4\%).

Conclusion: PHD was the most common causes of UGIB, then PUD. PUD was most common in middle age patients. However, PHD was more likely in patients having 41-60 years and older patients.

UGIB causes are variceal or nonvariceal. Non variceal causes of UGIBs include peptic ulcer disease (PUD), gastric/duodenal erosions, erosive esophagitis, Mallory Weiss tears and esophageal varices. Other lesser common causes include aortoenteric fistula, hemophilia, angiodysplasia, uremia, and coagulation disorders [3]. The commonest identified cause of UGIB is peptic ulcer. However, its incidence is declining thanks to the use of proton pump inhibitors (PPIs) besides the decreased prevalence of Helicobacter pylori infection. On the other hand, the variceal bleeding's relative contribution appears to be rising in the UK, it was found the cause of UGIB in $11 \%$ of admitted patients in the national audit [4].

UGIB is four times more frequent than Lower Gastrointestinal Bleeding (LGIB). It is associated with high morbidity; and mortality rate of about 6\%-10\% [5]. Mostly,-it -has -acute 
presentation as hematemesis and/or melena in $40 \%-50 \%$ of the cases (if the bleeding site is proximal to ligament of treitz); it may also present, chronically, as melena in $70 \%-80 \%$ of the cases (if the bleeding site is distal to ligament of treitz); or a less common presentation hematochezia in $10 \%$ of the cases in case of fresh LGIB [6].

It is extremely important to use risk scoring assessment system as early possible for triaging and prognostication of the patients with UGIB. Accurate risk stratification could enable urgent endoscopy and intensive care monitoring in case of high-risk patients also it could facilitate discharge of low-risk patients from emergency care units. Several risk-scoring systems are in use in clinical practice to predict clinical outcomes in patients with UGIB, however most of them are troublesome, require multiple variables including endoscopic data, and hence cannot be applied early [7]. It is crucial to have a basic overview on different UGIB conditions and to identify its major causes in our population.

Aim of the study: our aim was to assess the endoscopic findings in patients presenting with acute UGIB (melena with or without hematemesis) in Aswan university hospital.

\section{PATIENTS AND METHODS}

Study area: Aswan University Hospital has been recently established in parallel with the faculty of medicine in Aswan city, Upper Egypt in 2014. It serves patients from all over the Aswan governorate, in addition to referred patients from Luxor and Red Sea primary and secondary care units. The hospital comprises 33 clinical departments and 23 units in all specializations with more than 400 beds and 3000 employees. Instead of transferring patients to university hospitals in Assiut or Cairo governorates, patients could receive specialized qualified services in Aswan. According to the statistics of the hospital emergency facilities, patient transferring for receiving treatment outside Aswan has been decreased to less than 5\% (Aswan University Hospital; Official web page, 2019).

Study design and assessments: This study is a retrospective observational cross-sectional study. It included all endoscopy records of the Department of Tropical Medicine and Gastroenterology, Aswan University Hospital,
Aswan, Egypt, over a four years period from September 2015 to September 2019. A total of 1131 records of patients who presented to our endoscopy unit with manifestations of UGIB (Melena with or without hematemesis) as an indication of upper endoscopy were extracted after approval from the institutional review committee. Out of these records, 212 were excluded due to incomplete data. Remaining 918 records were scanned for patients with UGIB (Melena with or without hematemesis) as their indication to upper gastrointestinal endoscopy. Their age, gender, history of liver disease, nonsteroidal anti-inflammatory drugs (NSAIDs) as well as indication of upper endoscopy and detailed endoscopic findings were included in the record. The study was performed according to the ethical guidelines of the 1975 Declaration of Helsinki after approval from Institutional Review Board (IRB) at Aswan University Hospital.

Gastric and duodenal ulcers were classified according to Forrest classification into: Forrest Ia (ulcers with a spurting hemorrhage), Forrest $\mathrm{Ib}$ (ulcers with oozing hemorrhage), Forrest IIa (ulcers with a visible vessel), Forrest IIb (ulcers with adherent clot), Forrest IIc (ulcer with hematin on its base) and Forrest III (ulcers with clean base) [8].

\section{Statistical analysis:}

Data were collected, coded, revised then analyzed using the Statistical Package for Social Science (IBM SPSS) version 20. Numbers and percentages for the qualitative data in addition to mean, standard deviations and ranges were used for the presentation of quantitative data with parametric distribution while median with inter quartile range (IQR) were used for the quantitative data with nonparametric distribution. For comparison between groups Chi-square test was used for qualitative data while Fisher exact test was used when the expected count in any cell was less than 5. For comparison between two groups with quantitative data and parametric distribution independent t-test was used, while in case of quantitative data and non-parametric distribution Mann-Whitney test was used. Finally, for comparison between more than two groups with quantitative data and parametric distribution One Way Analysis of Variance (ANOVA) test was used, however KruskallWallis test was used for comparison between more than two groups with quantitative data and non-parametric distribution. The confidence 
interval was set to $95 \%$ and the accepted margin of error was set to $5 \%$. So, the p-value was considered significant as the following: $\mathrm{P}>0.05$ : Nonsignificant (NS) - P < 0.05: Significant (S) $\mathrm{P}<0.01$ : Highly significant (HS).

\section{RESULTS}

Our study included 918 patients who presented with UGIB, of which $62.6 \%$ (575) were male. Male to female ratio was $1.7: 1$. Their ages range from 6 to 80 years. The mean (SD) age of the study population was $48.33(15.29)$ years. Almost half of the patients $(n=430 ; 47 \%)$ who had UGIB belonged to the 41-60 years age group, followed by age group $>60$ years $(\mathrm{n}=$ $212 ; 23 \%)$ and $26-40$ years $(n=202 ; 22 \%)$, while the least common age group was $\leq 25$ years $(\mathrm{n}=74 ; 8 \%)$. Regarding the clinical presentation, $61.4 \%$ (564) of the cases presented with hematemesis with or without melena while $38.6 \%$ (354) presented with melena only. Moreover, $46.4 \%$ (426) of the patients had history of taking NSAIDs.

The endoscopic findings in the patients are shown in Table (1). The endoscopic findings could be divided into 3 main classes: peptic ulcer disease, portal hypertension and others. As shown in (Table 1), the most frequent endoscopic findings in our study were due to manifestations of portal hypertension PHD (55.5\%), it includes gastric varices $(\mathrm{GV})$, oesophageal varices $(\mathrm{OV})$ and portal hypertensive gastropathy (PHG). The second cause was peptic ulcer disease PUD (27.1\%) which included gastric ulcer (GU), gastritis and duodenal ulcer (DU). Other causes (17.4\%) include eosinophilic oesophagitis (EoE), Mallory Weiss syndrome (MW), gastric mass and gastric vascular telangiectasia (GVT). Some patients had multiple endoscopic findings, e.g. some patients suffered from oesophageal varices with gastric and duodenal ulcers, also most of patients with (EoE) suffered from gastritis and/or duodenitits. Gastric and duodenal ulcers were classified according to Forrest classification, the number of patients in each class is shown in (Table 1). The percentage of patients in each class according to the age group is shown in Table (2).

The interventions done to the patients are shown in (Table 3). Band ligation (BL) of oesophageal varices was done to almost $50 \%$ of patients either alone or with Injection Sclerotherapy (IS), 40.8\% didn't receive any intervention and $15 \%$ received IS.

The patients were divided into 3 groups according to their endoscopic finding: (PHD, PUD and Others). Upon comparing the patients' characteristics in the 3 groups of patients as shown in (Table 4), there were significant difference between the 3 groups regarding patient's sex, age and clinical presentation such that patients presented with hematemesis and melena were $72.9 \%, 46.9 \%$ and $61.3 \%$ of patients with PHD, PUD and other causes, respectively $(p<0.001) .69 \%$ of the PHD patients were male, while $61.5 \%$ of the "other causes" group was female. The patients with PHD were older than the other 2 groups. The history of liver diseases and use of NSAIDs were found highly significantly different between groups $(p<0.001$ for each) such that $93.3 \%$ of PHD had liver diseases history, while $62.5 \%$ of patients with PUD had history of NSAIDs use.

On the other hand, there were a highly significant difference in the type of endoscopic intervention done between the 3 groups $(p<0.001)$ as shown in (Table 5), such that about $85 \%$ of patients with PHD underwent (Band Ligation) BL with or without (Injection Sclerotherapy) IS, while patients with PUD and other causes had no intervention in $85 \%$ and $79.5 \%$ of them, respectively.

In the group of patients with PUD, DU and GU constitute $17.9 \%$ and $1.9 \%$, respectively of the UGIB causes. There were no statistically significant difference between the 2 groups of patients (with DU or GU) regarding sex, age and clinical presentation (hematemesis with melena or melena only), as shown in (Table 6). There was a statistically significant difference between DU and GU patients regarding history of liver diseases $(p=0.019)$, such that patients with GU had no history of liver diseases. The history of using NSAIDs was significantly different between the 2 groups $(p=0.009$ ), such that it was found in $73.9 \%$ and $44.4 \%$ of the DU and GU patients, respectively. No endoscopic intervention was made for the GU patients, while $28.7 \%$ of DU patients received AI+CLIP and $8.5 \%$ of them received AI only.

Patients with PHD were subdivided into OV, GV and $\mathrm{OV}+\mathrm{GV}$, they constitute $31 \%, 4.1 \%$ and $17.2 \%$ of the cases, respectively. There was no statistical significant difference between the 3 groups regarding age, while there was a highly 
significant difference between them regarding sex, clinical presentation, history of liver diseases, NSAIDs use and endoscopic intervention ( $p<0.001$ for each), as shown in (Table 7). About $75 \%$ of the patients in each of the $\mathrm{OV}$ and GV groups were male. The GV patients were mostly presented with melena only while in the other 2 groups, patients presented with hematemesis and melena. Almost all patients in the 3 groups have history of liver diseases $(89.1 \%, \quad 89.5 \%$ and $98.7 \%$, respectively). All the patients with GV didn't have history of using NSAIDs, while $3.6 \%$ of OV group and $47.5 \%$ of patients with $\mathrm{OV}+\mathrm{GV}$ used NSAIDs before. All the GV patients received IS, $98.6 \%$ of the OV patients received BL while $64.6 \%$ of the $\mathrm{OV}+\mathrm{GV}$ group received combination of both BL+IS.

Table (1): The frequency of clinical causes of UGIB in the studied patients.

\begin{tabular}{|c|c|c|c|c|}
\hline & & & No & $\%$ \\
\hline \multirow{10}{*}{ PUD } & \multirow{6}{*}{ DU } & DU FIA & 6 & $0.7 \%$ \\
\hline & & DU FII & 1 & $0.1 \%$ \\
\hline & & DU FIIA & 28 & $3.1 \%$ \\
\hline & & DU FIIB & 45 & $4.9 \%$ \\
\hline & & DU FIIC & 16 & $1.7 \%$ \\
\hline & & DU FIII & 68 & $7.4 \%$ \\
\hline & \multirow{2}{*}{ GU } & GU FIIC & 3 & $0.3 \%$ \\
\hline & & GU FIII & 15 & $1.6 \%$ \\
\hline & \multicolumn{2}{|c|}{ Duodenitis } & 62 & $6.7 \%$ \\
\hline & \multicolumn{2}{|c|}{ Gastritis } & 205 & $22.3 \%$ \\
\hline \multirow{4}{*}{ PHD } & \multicolumn{2}{|l|}{$\mathrm{OV}$} & 285 & $31.0 \%$ \\
\hline & \multicolumn{2}{|l|}{$\mathrm{GV}$} & 38 & $4.1 \%$ \\
\hline & \multicolumn{2}{|c|}{$\mathrm{OV}+\mathrm{GV}$} & 158 & $17.2 \%$ \\
\hline & \multicolumn{2}{|c|}{ PHG } & 363 & $39 \%$ \\
\hline \multirow{5}{*}{ Others } & \multicolumn{2}{|l|}{$\mathrm{EO}$} & 150 & $16.3 \%$ \\
\hline & \multicolumn{2}{|c|}{ MW } & 9 & $1.00 \%$ \\
\hline & \multicolumn{2}{|c|}{ Gastric mass } & 22 & $2.20 \%$ \\
\hline & \multicolumn{2}{|c|}{ Duodenal mass } & 8 & $0.90 \%$ \\
\hline & \multicolumn{2}{|c|}{ GVT } & 5 & $0.50 \%$ \\
\hline
\end{tabular}

Table (2): Summary of endoscopic findings in different age groups.

\begin{tabular}{|l|c|c|c|c|c|c|}
\hline \multirow{2}{*}{} & \multirow{2}{*}{ Number of patients } & \multirow{2}{*}{$\%$} & \multicolumn{4}{|c|}{ Age groups } \\
\cline { 4 - 7 } & & & $\leq 25$ years & $26-40$ years & $41-60$ years & $>60$ years \\
\hline All patients & 918 & $100 \%$ & $8 \%$ & $22 \%$ & $47 \%$ & $23 \%$ \\
\hline PHD & 509 & $55.5 \%$ & $4 \%$ & $7 \%$ & $60 \%$ & $29 \%$ \\
\hline PUD & 249 & $27.1 \%$ & $19 \%$ & $35 \%$ & $29 \%$ & $17 \%$ \\
\hline Others & 160 & $17.4 \%$ & $6 \%$ & $48 \%$ & $34 \%$ & $13 \%$ \\
\hline
\end{tabular}

Table (3): Endoscopic Intervention.

\begin{tabular}{|c|c|c|c|}
\hline \multirow{4}{*}{ Endoscopic Intervention } & No & \% \\
\hline \multirow{4}{*}{} & AI + CLIP & 48 & $5.2 \%$ \\
\cline { 2 - 4 } & BL & 332 & $36.2 \%$ \\
\cline { 2 - 4 } & BL+IS & 104 & $11.3 \%$ \\
\cline { 2 - 4 } & CLIP & 9 & $1.0 \%$ \\
\cline { 2 - 4 } & IS & 50 & $5.4 \%$ \\
\cline { 2 - 4 } & NO Intervention & 375 & $40.8 \%$ \\
\hline
\end{tabular}


Table (4): Comparison between finding with demographic data and history.

\begin{tabular}{|c|c|c|c|c|c|c|c|c|c|}
\hline & & \multicolumn{2}{|c|}{ PHD } & \multicolumn{2}{|c|}{ PUD } & \multicolumn{2}{|c|}{ Others } & \multicolumn{2}{|c|}{$\begin{array}{c}\text { Chi square test/ } \\
\text { One-way ANOVA }\end{array}$} \\
\hline & & No & $\%$ & No & $\%$ & No & $\%$ & $\mathbf{X}^{2} / \mathbf{f}^{*}$ & $P$ value \\
\hline \multirow{2}{*}{ SEX } & Male & 349 & $69.0 \%$ & 211 & $56.6 \%$ & 15 & $38.5 \%$ & \multirow{2}{*}{24.287} & \multirow{2}{*}{$<0.001$} \\
\hline & Female & 157 & $31.0 \%$ & 162 & $43.4 \%$ & 24 & $61.5 \%$ & & \\
\hline \multirow{2}{*}{ Age } & Mean (SD) & \multicolumn{2}{|c|}{$53.27(12.65)$} & \multicolumn{2}{|c|}{$41.53(15.94)$} & \multirow{2}{*}{\multicolumn{2}{|c|}{$49.26(15.68)$}} & \multirow{2}{*}{$73.390 *$} & \multirow{2}{*}{$<0.001$} \\
\hline & Range & \multicolumn{2}{|c|}{$6-77$} & \multicolumn{2}{|c|}{$14-80$} & & & & \\
\hline \multirow{2}{*}{ Presentation } & $\mathrm{H}$ and $\mathrm{M}$ & 369 & $72.9 \%$ & 175 & $46.9 \%$ & 20 & $51.3 \%$ & \multirow{2}{*}{63.077} & \multirow{2}{*}{$<0.001$} \\
\hline & M only & 137 & $27.1 \%$ & 198 & $53.1 \%$ & 19 & $48.7 \%$ & & \\
\hline \multicolumn{2}{|c|}{ History of liver disease } & 472 & $93.3 \%$ & 45 & $12.1 \%$ & 6 & $15.4 \%$ & 606.685 & $<0.001$ \\
\hline \multicolumn{2}{|c|}{ History of NSAIDs } & 175 & $34.6 \%$ & 233 & $62.5 \%$ & 18 & $46.2 \%$ & 67.115 & $<0.001$ \\
\hline
\end{tabular}

Bold indicates significance, H: Hematemesis; M: Melena

Table (5): Comparison between findings with endoscopic Intervention.

\begin{tabular}{|c|c|c|c|c|c|c|c|c|c|}
\hline & & \multicolumn{2}{|c|}{ PHD } & \multicolumn{2}{|c|}{ PUD } & \multicolumn{2}{|c|}{ Others } & \multicolumn{2}{|c|}{ Chi square test } \\
\hline & & No & $\%$ & No & $\%$ & No & $\%$ & $\mathbf{X}^{2}$ & $P$ value \\
\hline \multirow{6}{*}{ Intervention } & $\mathrm{AI}+\mathrm{CLIP}$ & 0 & $0.0 \%$ & 48 & $12.9 \%$ & 0 & $0.0 \%$ & \multirow{6}{*}{970.359} & \multirow{6}{*}{$<0.001$} \\
\hline & $\mathrm{BL}$ & 328 & $64.8 \%$ & 4 & $1.1 \%$ & 0 & $0.0 \%$ & & \\
\hline & $\mathrm{BL}+\mathrm{IS}$ & 104 & $20.6 \%$ & 0 & $0.0 \%$ & 0 & $0.0 \%$ & & \\
\hline & CLIP & 0 & $0.0 \%$ & 1 & $0.3 \%$ & 8 & $20.5 \%$ & & \\
\hline & IS & 50 & $9.9 \%$ & 0 & $0.0 \%$ & 0 & $0.0 \%$ & & \\
\hline & Normal & 24 & $4.7 \%$ & 320 & $85.8 \%$ & 31 & $79.5 \%$ & & \\
\hline
\end{tabular}

Bold indicates significance.

Table (6): Comparison between PUD with demographic data and history.

\begin{tabular}{|c|c|c|c|c|c|c|c|}
\hline & & \multicolumn{4}{|c|}{ PUD } & \multirow{2}{*}{\multicolumn{2}{|c|}{$\begin{array}{l}\text { Chi square test/ } \\
\text { Independent t test }\end{array}$}} \\
\hline & & \multicolumn{2}{|c|}{ DU } & \multicolumn{2}{|c|}{ GU } & & \\
\hline & & No & $\%$ & No & $\%$ & $\mathrm{X}^{2} / \mathrm{t}^{*}$ & P value \\
\hline \multirow{2}{*}{ Sex } & Male & 106 & $64.6 \%$ & 8 & $44.4 \%$ & \multirow{2}{*}{2.825} & \multirow{2}{*}{0.092} \\
\hline & Female & 58 & $35.4 \%$ & 10 & $55.56 \%$ & & \\
\hline Age & Mean (SD) & \multicolumn{2}{|c|}{$48.33(15.28)$} & \multicolumn{2}{|c|}{$47.48(12.37)$} & $-0.228^{*}$ & 0.820 \\
\hline \multirow{2}{*}{ Presentation } & $\mathrm{H}$ and $\mathrm{M}$ & 74 & $45.1 \%$ & 8 & $44.4 \%$ & \multirow{2}{*}{0.003} & \multirow{2}{*}{0.956} \\
\hline & M only & 90 & $54.9 \%$ & 10 & $55.56 \%$ & & \\
\hline \multirow{2}{*}{ History of liver disease } & No & 125 & $76.2 \%$ & 18 & $100 \%$ & \multirow{2}{*}{5.448} & \multirow{2}{*}{0.019} \\
\hline & Yes & 39 & $23.8 \%$ & 0 & $0.0 \%$ & & \\
\hline \multirow{2}{*}{ History of NSAIDs } & No & 43 & $26.1 \%$ & 10 & $55.56 \%$ & \multirow{2}{*}{6.763} & \multirow{2}{*}{0.009} \\
\hline & Yes & 121 & $73.9 \%$ & 8 & $44.4 \%$ & & \\
\hline \multirow{2}{*}{ Endoscopic Intervention } & $\mathrm{AI}+\mathrm{CLIP}$ & 47 & $28.7 \%$ & 0 & $0.0 \%$ & \multirow{2}{*}{ NA } & \multirow{2}{*}{ NA } \\
\hline & $\mathrm{BL}$ & 14 & $8.5 \%$ & 0 & $0.0 \%$ & & \\
\hline
\end{tabular}

Bold indicates significance, H: Hematemesis; M: Melena 
Table (7): Comparison between PHD with demographic data and history.

\begin{tabular}{|c|c|c|c|c|c|c|c|c|c|}
\hline & \multicolumn{6}{|c|}{ PHD } & \multirow{2}{*}{\multicolumn{2}{|c|}{$\begin{array}{c}\text { Chi square test/ } \\
\text { One-way } \\
\text { ANOVA } \\
\end{array}$}} \\
\hline & & \multicolumn{2}{|c|}{ OV } & \multicolumn{2}{|c|}{ GV } & \multicolumn{2}{|c|}{$\mathrm{OV+GV}$} & & \\
\hline & & No & $\%$ & No & $\%$ & No & $\%$ & $\mathbf{X}^{2} / \mathbf{f}^{*}$ & $P$ value \\
\hline \multirow{2}{*}{ Sex } & Male & 214 & $75.1 \%$ & 29 & $76.3 \%$ & 80 & $50.6 \%$ & \multirow{2}{*}{29.129} & \multirow{2}{*}{0.001} \\
\hline & Female & 71 & $24.9 \%$ & 9 & $23.7 \%$ & 78 & $49.4 \%$ & & \\
\hline Age & Mean (SD) & \multicolumn{2}{|c|}{$53.78(11.32)$} & \multicolumn{2}{|c|}{$52.61(11.79)$} & \multicolumn{2}{|c|}{$51.99(15.63)$} & $1.004 *$ & 0.367 \\
\hline \multirow{2}{*}{ Presentation } & $\mathrm{H}$ and $\mathrm{M}$ & 218 & $76.5 \%$ & 13 & $34.2 \%$ & 125 & $79.1 \%$ & \multirow{2}{*}{34.347} & \multirow{2}{*}{0.001} \\
\hline & M only & 67 & $23.5 \%$ & 25 & $65.8 \%$ & 33 & $20.9 \%$ & & \\
\hline \multirow{2}{*}{ History of liver disease } & No & 29 & $10.2 \%$ & 4 & $10.5 \%$ & 2 & $1.3 \%$ & \multirow{2}{*}{12.605} & \multirow{2}{*}{0.001} \\
\hline & Yes & 256 & $89.1 \%$ & 34 & $89.5 \%$ & 156 & $98.7 \%$ & & \\
\hline \multirow{2}{*}{ History of NSAIDs } & No & 195 & $68.4 \%$ & 38 & $100.0 \%$ & 83 & $52.5 \%$ & \multirow{2}{*}{32.931} & \multirow{2}{*}{0.001} \\
\hline & Yes & 90 & $31.6 \%$ & 0 & $0.0 \%$ & 75 & $47.5 \%$ & & \\
\hline \multirow{4}{*}{ Endoscopic Intervention } & $\mathrm{AI}+\mathrm{CLIP}$ & 1 & $0.4 \%$ & 0 & $0.0 \%$ & 0 & $0.0 \%$ & \multirow{4}{*}{653.331} & \multirow{4}{*}{0.001} \\
\hline & $\mathrm{BL}$ & 281 & $98.6 \%$ & 0 & $0.0 \%$ & 48 & $30.4 \%$ & & \\
\hline & BL+IS & 2 & $0.7 \%$ & 0 & $0.0 \%$ & 102 & $64.6 \%$ & & \\
\hline & IS & 0 & $0.0 \%$ & 38 & $100.0 \%$ & 8 & $5.1 \%$ & & \\
\hline
\end{tabular}

Bold indicates significance, H: Hematemesis; M: Melena

\section{DISCUSSION}

In our study, the mean age of our patients was 48.33 years. This was slightly lower than the mean age of UGIB patients reported in other studies [9-11]. The majority of the patients (47\%) were in the age group 41-60 years, followed by age group $>60$ years $(\mathrm{n}=212 ; 23 \%)$ and 26-40 years $(\mathrm{n}=202 ; 22 \%)$, the least common age group was less than or equals to 25 years $(\mathrm{n}=74 ; 8 \%)$. The distribution of patients in each age group resembles that of [12]. This may be due to higher ratio of older population in western world. Moreover, we found that UGIB was more common in male patients than females, with a male to female ratio of $1.7: 1$. This is the same as that of Malghani in Pakistan, and comparable to the data reported in other studies in which male patients having UGIB was greater than females, in different populations $[\mathbf{1 1}, \mathbf{1 3}, \mathbf{1 4}]$.

As reported repeatedly, the most common and important cause of UGIB found in our patients was portal hypertension (55.5\%) especially esophageal varices which constitutes alone about $48.2 \%$ of the cases either alone or with gastric varices. This finding goes with Malghani who reported $50.8 \%$ for esophageal varices and Gouda who reported $53.3 \%$ [11,15]. In the second rank comes peptic ulcer disease with percentage equals $27.1 \%$ of the cases, this goes with Gouda who reported 24.9\% [15]. The endoscopic findings of peptic ulcer (gastric and duodenal ulcer) were only found in $6.1 \%$ of patients in Malghani's study. Similar results were reported in international studies as well [11,16-18]. In contrast to our study findings, several other studies showed peptic ulcer disease as the most common cause of UGIB. Peptic ulcer is more common than esophageal varices in western world [19-22]. Regarding the endoscopic finding in relation to age, PHD was found to be high in patients having 41-60 years and older, while the middle aged patients represented the majority of patients having PUD and other causes of UGIB (mainly EO), in contrast to Malghani et al., 2019 who found that variceal bleeding had a significant association with middle age group patients, while duodenal ulcer bleeding had a significant association with older age.

The high prevalence of esophageal varices in our population might be due to the high prevalence of viral hepatitis (HBV \& HCV) related cirrhosis [15]. Comparable results to our study are also found in other local studies [15] and in other populations who suffer from high incidence of viral hepatitis as well [23].

Most of the patients with PHD (73\%) were presented with hematemesis and melena, and almost all of them had previous history of liver diseases. Since HCV infection is endemic in Egypt with the highest prevalence rate in the world leading to cirrhosis and HCC [24], this 
may encounter for the high incidence of PHD in Egypt. OV patients were mostly presented with hematemesis and melena, while GV patients were mostly presented with melena only.

More than two-thirds of all bleeding episodes in patients with liver cirrhosis are caused by esophageal variceal hemorrhage [25]. Variceal hemorrhage leads to a significant mortality rate of $7 \%-15 \%$ [26]. So, it is recommended that every patient with liver cirrhosis and symptoms suggesting UGIB should be managed as having variceal hemorrhage until a definite diagnosis is made by upper endoscopy.

About one half (46.4\%) of our patients had history of taking NSAIDs. It is worth mentioning that $75 \%$ of duodenal ulcer patients were receiving NSAIDs which is known as a risk factor for peptic ulcer. NSAID-induced GI mucosal injury can range from mild gastritis to further development of complicated peptic ulcer disease [27]. NSAIDs also decrease platelet aggregation which increases the risk for portal hypertensive hemorrhage particularly in those with cirrhosis [28]. This may encounter for the observed high percentage of GI bleeding patients taking NSAIDs either with PUD or PHD.

About $85 \%$ of PHD patients needed band ligation with or without injection sclerotherapy, while $85 \%$ of PUD patients didn't need any intervention, they only received suitable medication. Most patients of group of others (non PHD or PUD) $(79.5 \%)$ didn't need any intervention while only $20.5 \%$ needed Clip insertion.

Our study could be a good representative of the general population because it was carried out at a tertiary care hospital and it is the only qualified centre for these governorates. However, some patients suffered from milder symptoms may not be referred to our hospital. Also, this was a single centre study; further multiple studies targeting centres providing upper gastrointestinal endoscopy services should be taken in consideration for further improving our knowledge and concept toward different etiologies of UGIB.

\section{CONCLUSION}

Our study revealed that patients presenting to emergency department with UGIB were more likely to be males. Esophageal varices were the most frequent cause of UGIB while bleeding due to duodenal ulcer was relatively uncommon as compared to the western populations. PHD was more likely to be the cause of UGIB in male patients. On the other hand, female UGIB patients were more likely to have findings of PUD and other causes on EGD. PUD was most common in middle age patients. However, PHD was more likely to be found in patients having 41-60 years and older patients.

\section{Abbreviations:}

Adrenaline Injection (AI)

Band Ligation (BL)

Eosinophilic Oesophagitis (EoE)

Esophagogastroduodenoscopy (EGD)

Forrest Classification (F)

Gastric Ulcer (GU)

Gastric Varices (GV)

Gastric Vascular Telangiectasia (GVT)

Injection Sclerotherapy (IS)

Institutional Review Board (IRB)

Inter Quartile Range (IQR)

Lower Gastrointestinal Bleeding (LGIB)

Mallory Weiss Syndrome (MW)

Non-Steroidal Anti-Inflammatory Drugs

(NSAID)

Oesophageal Varices (OV)

Peptic Ulcer Disease (PUD)

Portal Hypertension (PHT)

Portal Hypertensive Gastropathy (PHG)

Proton Pump Inhibitors (PPI)

Statistical Package for Social Science (SPSS)

Upper Gastrointestinal Bleeding (UGIB)

\section{Ethical Approval:}

The study was performed according to the ethical guidelines of the 1975 Declaration of Helsinki after approval from Institutional Review Board (IRB) for human subject research at Aswan University Hospital.

Funding: Authors didn't receive any fund.

Conflict of interest: The authors have no conflict of interest to declare.

\section{REFERENCES}

1. Stanley AJ, Laine L. Management of acute upper gastrointestinal bleeding. BMJ 2019; 364.

2. Nelms DW, Pelaez CA. The Acute Upper Gastrointestinal Bleed. Surg Clin North Am 2018; 98(5):1047-57.

3. McPhee SJ, Papadakis MA, Tierney LM. Current medical diagnosis \& treatment. 47th ed. 
Tierney LM, editor. San Francisco: McGrawHill Medical; 2008. 916 p.

4. Farrar FC. Management of Acute Gastrointestinal Bleed. Crit Care Nurs Clin North Am 2018; 30(1):55-66.

5. Fallah MA, Prakash C, Edmundowicz S. Acute gastrointestinal bleeding. Med Clin North Am 2000; 84(5):1183-208.

6. Hadayat R, Jehangiri A ur R, Gul R, Khan AN aseer, Said K, Gandapur A. Endoscopic findings of upper gastrointestinal bleeding in patients with liver cirrhosis. J Ayub Med Coll 2015; 27(2):391-4.

7. Thandassery RB, Sharma M, John AK, Al-Ejji KM, Wani H, Sultan K, et al. Clinical application of AIMS65 scores to predict outcomes in patients with upper gastrointestinal hemorrhage. Clin Endosc 2015; 48(5):380-4.

8. Kim DS, Jung Y, Rhee HS, Lee SJ, Jo YG, Kim $\mathrm{JH}$, et al. Usefulness of the forrest classification to predict artificial ulcer rebleeding during second-look endoscopy after endoscopic submucosal dissection. Clin Endosc 2016; 49(3):273-81.

9. Zaltman C, De Souza HSP, Castro MEC, Sobral $M$ de FS, Dias PCP, Lemos V. Upper gastrointestinal bleeding in a Brazilian hospital: A retrospective study of endoscopic records. Arq Gastroenterol 2002; 39(2):74-80.

10. Theocharis GJ, Thomopoulos KC, Sakellaropoulos G, Katsakoulis E, Nikolopoulou V. Changing trends in the epidemiology and clinical outcome of acute upper gastrointestinal bleeding in a defined geographical area in Greece. J Clin Gastroenterol 2008; 42(2):12833.

11. Malghani WS, Malik R, Chaudhary FMD, Tameez Ud Din A, Shahid M, Ahmad S, et al. Spectrum of Endoscopic Findings in Patients of Upper Gastrointestinal Bleeding at a Tertiary Care Hospital. Cureus 2019 [cited 2020 Mar 14]; 11(4):e4562. Available from: doi:10.7759/cureus.4562

12. Mohammad S, Chandio B, Shaikh A, Soomro AA, Rizwan A. Endoscopic Findings in Patients Presenting with Upper Gastrointestinal Bleeding. Cureus 2019; 11(3):4-9.

13. Mustapha S, Ajayi N, Jibrin Y, Shehu A. Aetiology of Upper Gastrointestinal Bleeding in North-Eastern Nigeria: A Retrospective Review of Endoscopic Findings. Niger J Gastroenterol Hepatol 2009 [cited 2020 Mar 14];1:75-8. Available from: https://www.ajol.info/index.php/njgh/article/vie w/77321

14. Rockall TA, Logan RFA, Devlin HB, Northfield TC. Incidence of and mortality from acute upper gastrointestinal haemorrhage in the United Kingdom. BMJ 1995; 311(6999):222.

15. Gouda M kamel, Esmat G, Doss W. Acute upper gastrointestinal bleeding in Kasr El Aini gastrointestinal endoscopy uint in the last 10 years. cairo univ. 2002; Available from: https://www.cu.edu.eg/thesis_pdf/7125

Thesis_Acute upper gastrointestinal bleeding in.pdf

16. Sarwar S, Dilshad A, Khan AA, Alam A, Butt AK, Tariq S, et al. Predictive value of Rockall score for rebleeding and mortality in patients with variceal bleeding. J Coll Physicians Surg Pakistan 2007; 17(5):253-6.

17. Dewan KR, Patowary BS, Bhattarai S. A study of clinical and endoscopic profile of acute upper gastrointestinal bleeding. Kathmandu Univ Med J 2014; 12(45):21-5.

18. Suba M, Ayana SM, Mtabho CM, Kibiki GS. The aetiology, management and clinical outcome of upper gastrointestinal bleeding among patients admitted at the kilimanjaro christian medical centre in Moshi, Tanzania. Tanzan J Health Res 2010; 12(4).

19. Boåianu AM, Matei D, Tanåãu M, Acalovschi M. Mortality and need of surgical treatment in acute upper gastrointestinal bleeding: A one year study in a tertiary center with a 24 hours / day-7 days / week endoscopy call. Has anything changed? Chir 2013; 108(3):312-8.

20. Singh SP, Panigrahi MK. Spectrum of upper gastrointestinal hemorrhage in coastal Odisha. Trop Gastroenterol 2013; 34(1):14-7.

21. Gurung RB, Joshi G, Gautam N, Pant P, Pokhrel B, Koju R, et al. Upper gastro-intestinal bleeding: Aetiology and demographic profile based on endoscopic examination at Dhulikhel hospital, Kathmandu university hospital. Kathmandu Univ Med J 2010; 8(30):208-11.

22. Gaudong Mbethe GL, Mounguengui D, Ondounda M, Magne C, Bignoumbra R, Ntsoumou $\mathrm{S}$, et al. Profil épidémiologique des hémorragies digestives hautes au Gabon. Med Sante Trop 2014; 24(4):441-3.

23. Pasha M, Hashir M, Pasha A, Pasha M, Raza A, Fatima M. Frequency of esophageal varices in patients with upper gastrointestinal bleeding. Pak J Med Sci 2011 [cited 2020 Mar 14];27:277-81. Available from: 
https://www.researchgate.net/publication/22849 5354_Frequency_of_esophageal_varices_in_pati ents_with_upper_gastrointestinal_bleeding

24. Elgharably A, Gomaa AI, Crossey MME, Norsworthy PJ, Waked I, Taylor-Robinson SD. Hepatitis C in Egypt - past, present, and future. Int J Gen Med 2017;10:1-6.

25. D'Amico G, De Franchis R. Upper digestive bleeding in cirrhosis. Post-therapeutic outcome and prognostic indicators. Hepatology 2003; 38(3):599-612. Available from: https://doi.org/10.1053/jhep.2003.50385

26. Biecker E. Gastrointestinal Bleeding in Cirrhotic Patients with Portal Hypertension. Yang S-S, Zheng M-H, Castiella A, editors. ISRN Hepatol
2013; 2013:541836. Available from: https://doi.org/10.1155/2013/541836

27. Drini M. Peptic ulcer disease and non-steroidal anti-inflammatory drugs. Aust Prescr 2017; 40(3):91-3.

28. Malespin MH. Risk of Nonsteroidal Antiinflammatory Drugs and Safety of Acetaminophen in Patients with Advanced Liver Disease. Clin Liver Dis. 2018 [cited 2020 Mar 14]; 12(3):85-8. Available from: https://onlinelibrary.wiley.com/doi/abs/10.1002/ cld.737 